\title{
Exploring the Importance of Early Alert Programs in Improving Learning in Selected Public Universities in South Africa
}

\author{
Prof. S. M Kang'ethe \\ University of Fort Hare, Department of Social Work and Social Development \\ Box X1314, Alice 5700, South Africa \\ Email: skangethe@ufh.ac.za \\ Dr Patricia Muhuro \\ Senior Consultant, Teaching and Learning Centre, University of Fort Hare \\ Email: pmuhuro@ufh.ac.za
}

\section{Doi:10.5901/mjss.2014.v5n23p1099}

\begin{abstract}
While many student retention and support programs are already in place in higher education, the unrelenting challenge of high student drop out in the first year of study requires scrutiny of the perceived promising high impact programs through empirical research. This paper which is part of a larger project on the implementation of student retention programs, explored the implementation of one promising retention program called "early warning or alert" in two conveniently selected public universities. A mixed method approach was used whereby qualitative data and quantitative data were corroborated at data collection and analysis stages. Data were gathered from four purposively selected student retention institutional leaders. These leaders responded to in-depth interviews. The research also heavily sought institutional documents for document analysis. The findings were analysed inductively and presented thematically. The study found that early alert programs were an important national strategy for improving students' performance and retention. The alert program improved decision making, planning and allocation of resources. However, program marketing, lack of professional capacity to handle all the required processes and negative students' attitudes towards the program were found to beset the programme success. The study recommends that public universities increase individuals providing alert and intervention processes, and to orient students about the program.
\end{abstract}

Keywords: Early alert, public higher education, orientation programmes, freshmen, support programmes, Student tracking and monitoring programmes

\section{Introduction and Background to the Study}

Realistically, any feasible and sound educational endeavour requires that its goals be constantly monitored. This allows for the education providers and policy makers to make improvements where necessary. Student tracking and monitoring through early alert programs seem to offer a promising solution to the eminent challenge of high student dropout that higher education institutions are currently experiencing. Makura, Skead and Nhundu (2011) argue that student drop out is attributed to lack of student support. This is because early alert program has such features as identifying students who are not performing according to expected standard, then proactively contact them and channel them to appropriate support through intervention (Tampke, 2012; Du Plessis, 2005; Ewell, 1995). Tinto (2005) is of the view that the levels of student engagement with the academic and social settings have a greater influence on student retention than the preentry attributes. Therefore, it is particularly important that higher education managers make use of cost effective strategies to retain students. For South Africa, ensuring that students who are admitted to higher education are supported is one of the important policy imperatives outlined by the higher education act (DOE, 1997). This is important in South Africa because of the eminent challenges of students taking too long to complete the registered programmes and low retention in the first year of study among the formerly disadvantaged social groups ( Scott, Yeld \& Hendry, 2007, Letseka \& Maile, 2008; CHE, 2012). An empirical study on the essence of early alert programs, then, becomes important.

\section{Problem Statement}

So many fingers are being pointed at higher education because of its apparent mal performance in its task of managing 
and implementation of education policies (Skead, Makura \& Nhundu, 2011). This is because of higher attrition rate experienced with many students especially from disadvantaged social groups (Scott, Hendry \& Yeld, 2007). This points to the fact that the educational processes at all levels may be lacking tracking, or if it is in place, not much is being done to do it effectively and efficiently. This, therefore, justifies the need for empirical research investigation to find out the extent to which the educational programmes and processes in some higher educational institutions are tracked.

\section{Methodology}

\subsection{Research Paradigm and Design}

The study adopted a mixed method approach grounded in the post positivist paradigm. According to Bergman (2008), mixed method researchers focus on combining qualitative and quantitative data in a single study. However, the study was dominantly qualitative. Johnson and Christensen (2011) assert that mixed method connect theory and practice and this assists in understanding multiple causalities in a phenomenon. A pragmatic stance was adopted in that the research objectives determined the type of data to be collected (Cresswell, 2009). On specific design, the study used a case study and a mini survey designs.

\subsection{Research Methods}

The study adopted interviews and document analysis. The document analysis ensured that the researchers obtained description of trends, frequencies and interrelationships, among the various activities done in the program including statistical analysis (Sarantakos, 2005). Document analysis enabled scrutiny of less subjective information through analysis of retention policies, plans and reviews. This is because Tinto (2005) asserts that a clear retention plan ensures effective implementation of the goals. The use of documents offered other advantages highlighted in literature such as authenticity, and low cost and retrospectively (Cresswell, 2009).

However, the researcher was aware of the flaws of document analysis with respect to currency of information, accessibility of confidential data which could result in misleading data can easily affect study results (Sarantakos, 2005). Semi-structured interviews corroborated findings from the document analysis by clarifying ambiguous issues (Tashakkori \& Teddlie, 2009). Each interview lasted about fourty- five minutes. The interviews were conducted in the offices of the respective participants so as to ensure that participants feel more comfortable in their natural environment.

\subsection{Sampling Frame}

The sampling frame composed of lists of staff working in different programs and the list of students registered with these two universities. Precisely, the sampling frames for the study was fourty two thousand students and approximately six thousand staff members.

\subsection{Unit of Analysis}

The early alert program was the unit of analysis. All the information sought in the study centred among the purpose, processes, and assessment practices used when implementing the program in the two institutions. Therefore, four alert program leaders provided the required data.

\subsection{Sample selection and procedures}

The participants for the study were purposively sampled from those leading student retention initiatives in the institution. Purposive sampling was a cost effective method of collecting data from individuals possessing typical characteristics of the issue under investigation (Bergman, 2008). In this study, it was important to select the tracking leaders because they had a clearer understanding of the conceptualization of the program as well as firsthand experience in the program implementation processes.

\section{Research Domain}

Although there are twenty three public universities in South Africa, the study was mainly interested in universities with 
large enrollments and located in rural settings. Specifically, the characteristic of being public universities implies that open access policies are used when enrolling students. This also implies that a large number of none traditional students such as first generation, mature students, nonresident students are admitted. This could also point to the fact that students' background characteristics may influence how they perform because of their unique circumstances, thus raising the need for increased and effective students monitoring of their academic progression. To be precise, most Public universities are located in rural, urban and peri urban settings. Those universities located in rural settings also usually have a larger student population body drawn from rural communities in most parts of Africa. This characteristic may imply that the majority of the students may not be adequately prepared for higher education due to the limited availability of learning resources (Lemmens, 2010;Letseka \& Breier, 2007). Therefore, most of the students are likely to have academic preparation as the key potential dropout risk factor. Specifically, the research site comprised of two universities that were conveniently sampled out from the twenty three public universities in South Africa. The selection criteria considered was rural location, having a student enrollment of more than ten thousand students and willingness of the institutional administrators to participate in the study.

\section{Ethical and Legal Considerations}

A letter of permission obtained from the research ethics committees of the two institutions was used to gain access. Apart from the permission from the gatekeepers, permission was also sought from each of the participants who voluntarily participated in the study (Seale, 2012). This was achieved though a letter explaining the purpose of the study and an accompanying consent form to confirm willingness to participate. The researchers upheld the confidentiality of participants by using codes and pseudonyms when presenting and reporting on the data (Bergman, 2008). Participants were not compelled to disclose information. Interviews were tape recorded pending approval and consent of the respective respondents. The researcher took notes in instances where participants rejected to be voice recorded.

\section{Data Analysis and Interpretation}

The data was analysed inductively. This means that emerging themes were coded, and placed into appropriate categories . Data was presented using verbatim responses where appropriate.

\section{Data Credibility and Trustworthiness}

Trustworthiness has to deal with the way the researcher claims that the research is "worth paying attention to" or accurate (Leedy \& Ormroid, 2010). This was achieved through member checking. Also, all the interviews were tape-recorded so as to capture full details of the conversations. In instances where the respondents were uncomfortable to be recorded, field notes were used ( , 2012). The use of multiple methods also ensured that the weakness of one method was countered by other methods.

\section{Limitations of the Study}

Student tracking and monitoring is a strategy that has many approaches (Kuh et al., 2007c). Therefore, findings concerning the challenges and successes of tracking may be confined to specific contexts. The data for the study was collected in 2011 and it is possible that tracking practices have changed. However, some of the findings and suggestions could still be relevant to those institutions that are still battling with introducing early alert systems as well as strengthening the existing ones. The researcher held interviews with four administrators involved in student tracking, but omitted staff and students who could have provided more insight on the phenomenon of early alert.

\section{Findings}

\subsection{Tracking is a response to national obligations and policies}

Findings from document analysis indicated that institutions of higher learning were required to effectuate tracking of all the students in their institutions. The rationale behind the student tracking system was to assist institutions in identifying weaker students at an early stage so as to institute interventions. This was evidenced by the following excerpt from the strategic plan at WW. 
This [tracking and monitoring system] system has been ... also extensively applied in the higher education sector... The strategy compliments such efforts on WW responsiveness to national imperatives, .. which is funded by the Ministry of Education (WW_TKM1).

The above findings also indicate that student tracking was not only applied at the institutions under study, but to the wider higher education community and had support from the Department of Higher Education and Training. It was also important to find out how the tracking administrators perceived the importance of tracking.

\subsection{Tracking offers institutions an opportunity to interrogate and consume data}

The findings also indicated that tracking offered an opportunity for institutions to consume, interrogate, and make use of the recorded data. Notably, many institutions of higher learning safeguard data in the South African national database for higher education institutions known as the Higher Education Management Information System (HEMIS).

We keep a record of all student data that is captured during enrolment in the HEMIS database. The same system can extract student demographics, previous schooling details, finance information, and current academic performance for each semester. We actually did a preliminary study with one cohort and found that students from certain backgrounds had higher chances of completing their studies than others even get the results of tests and assignments if the lecturers record the information on the system (FF_TKM1).

The responses above show that the HEMIS database, a national database for managing students' records was used to record all students' background information which encompassed demographics, high school results, and current courses. The response also shows attempts to interrogate historical data with a specific cohort. This kind of information could possibly inform enrollment management for future cohorts as it is a noble attempt to use tracking for predictive purposes. Perhaps initiating student identification based on historical data such as performance in the previous year after the first three weeks could ensure that support is immediately provided to all students to allow sufficient time to improve.

\subsection{Tracking is a tool of planning and bolstering decision making on educational output}

The findings emanating from document analysis of institutional policies and strategic plans indicated that early alert programs have potential to enhance optimal utilization and allocation of resources. The documents also emphasized the need to assess the accomplishment of the goals. However, there were no clear deliverables on how the output from the tracking program was to be assessed. This is a gap which perhaps needs to be addressed by identifying clear deliverables.

\subsection{Co-ordinated support and goodwill important for success of alert program}

On tracking of student programmes, findings from the tracking leaders highlighted the importance of the co-ordination among the stakeholders. This was because several people were involved in the different processes. This was evidenced by the following responses.

The new system being tested is under the HEMIS co-orinator, but the tracking and monitoring specialist are able to access the database and produce required reports. They have to work closely with faculties who provide the data from student assessments. Faculites also have a part to play in the monitoring of students( WW TM1)

The system was developed through the SANTED project but has not yet been in use. The tracking system has not been fully functional due to limited staff. We have however appointed two new staff members who will be training the staff to use the system as well as research on the program outcomes ( FF-TM2)

The finding from FF points to the importance of ensuring that the model being used suits the context. In the above scenario resource constraints negatively affected the proper implementation of the early alert program as they were no specialist to train the rest of the staff on the program. Given the low staff ratios it is most likely that staff have to the tasks of assessing, marking and recording alerts without much extra assistance. This can possibly limit timely dissemination of alerts. In these researchers' perspectives, depending on external funding points to financial hurdles, making the government to intervene and using a lot of public funds to rescue them.

The findings from WW above emphasize on the importance of goodwill by the whole institutional community so that tracking can be expedited with ease. This prompts and challenges the institutional management to put tracking as 
one of the most important agenda that can bolster the institutions planning and decision making processes.

\subsection{Students response to alert critical for program success}

Findings from the interviews indicated that alerts were mainly dependent on student academic performance. Any student who obtained marks below $50 \%$ was deemed potentially at risk, and had to be intrusively advised. This is highlighted by the following response:

If a student got marks below 50\%, he/she is required to hold a meeting with a career and guidance counsellor. The career and guidance counsellor assesses the intensity of the student's challenges and recommends a plan of action. The counsellor then makes referral so that the student receives support from the relevant personnel depending on the nature of the problem. The counselor keeps a record of of all referrals and this information is used in making a consession for thos students who may fail in the following terms. If we find that the student was not active in the intervention sessions, the ADC staff have to write a report to be handed to the committee that send students away (WW_TKM1).

As can be noted from the responses above, the tracking system at WW was multi-sectorial. This was a cumbersome process that required co-operation of the lecturers, the exams department, and the counsellors. In principle, the manual process involved having the tracking specialist extract names of students and their marks from the HEMIS database, in consultation with the examination department. The tracking specialist would then use statistical models to classify students' level of risk, paying attention to courses where the mark was less than $50 \%$. Details of students who were flagged as at risk were sent to the Blackboard administrator who sent out emails to such students to indicate that they were at risk. The email directed the student to see the career guidance counselor, or psychologist, who would recommend an appropriate intervention.

We have several challenges both on the student and staff sides. Some of our students do not read their emails and delay in honoring set appointments. Others just turn up for counselling sessions a few times. On the staff side we have noted that the advisors do not always attend to all students. This is because they are thinly spread and some have to resort to group advising. We feel that this approach is not always ideal but they are also overworked. (WW_TKM1)

However, it can also be noted that the challenge of students' response to outreach negatively affected the program goals. On the other hand, staff shortages limited the implementation of individualized attention.

\section{Discussion of the Findings}

Student tracking and monitoring is viewed as an important student retention strategy in South Africa. This is evidenced by the involvement of the government in the funding of the program initiatives in institutions of higher learning. This is perhaps one strategy to bolster students' throughputs given that the documented evidence that the investigated universities experiences low student retention of around 15\% as noted by the Human Resources Research Council (HSRC) (Letseka \& Maile, 2008). According Makura, Skead and Nhundu (2011), this low student throughput is a result poor student support. Monitoring learning process is also a powerful way of supporting students learning process. This places tracking as a very important intervention to identify students' needs and support them to gain the right quality of graduate attributes. Bolstering learning through improved graduate attributes increases the number of professionals to meet the social, economic and technological needs of the country. This is because South Africa has been experiencing a shortage of qualified professionals in some fields, with some graduates also accused of not meeting job expectations. This presents a sorry state of affairs to the country especially to the international community. Therefore, strong interventions such as effective tracking could promise to turn around this dreadful phenomenon.

The findings have shown that alert programs are enabling institutions to interogate institutional data to improve planning and decision making as highlighted by Ewell (1995). In this study, a national database was in place to keep a record of various forms of data. One institution attempted to use the stored data for predicting completion. Using historical data as the initial source of tracking is important in that it curbs the challenge of missing students' alerts during the early part of the term. However, the findings also show increased reliance on academic indicators of performance as the major alert. This concurs with the observations made by Cuseo (2006) that academic issues remain the source of alerts in many alert programs. However Krause (2005) argues that it is important to make use of both academic and non academic indicators. 
The alert program at WW was highly structured in that the alerts were done at specific intervals. This approach is ideal in a centralized model and allows students follow up to be done systematically. However, the commencement of the alert in March could be regarded as late response to intervention because it us beyond the four weeks proposed by some retention scholars (Tinto, 1993, Siedman, 2005). Most scholars recommend that intervention begin in the fourth week because the first three weeks are a delicate period for most students. Such a scenario could accelerates chances for dropping out.

Findings from the study also reiterated the importance of positive response to alerts for the program success. It appears that the issue of poor communication and response by students is also an issue of conecern. Perhaps this is because outreach was mainly confined to few counselors. The high student staff ratios provided limited opportunities to build trusting relationships which are key in supporting students who are potentially at risk. In this vein, perhaps it is important to increase the number of the staff who provide outreach to include residence officials, student support staff and peers, as these have more contact with the students.

\section{Conclusion}

Institutions of higher learning have a mandate to support students they enroll. It is therefore important to monitor the achievement of educational goals through tracking students learning progress. The current study explored the importance of implementing a tracking and monitoring program in two public universities in South Africa. Participants were purposively sampled and consisted of tracking program managers who responded to interviews and also provided institutional documents outlining the retention plans, processes and outcomes. Data was triangulated by corroborating responses from interviews and document analysis. The study found that early alert programs were an important national strategy for improving students' performance and retention. The alert program improved decision making, planning and allocation of resources. Despite the potential benefits of early alert programs, the enactment of the program goals were usually hampered by poor program marketing, lack of professional capacity to handle all the required processes and negative students' attitudes towards the program.

\section{Recomendations}

The study recommends that institutions of higher learning market the early alert program to students as soon as they enroll for them. This is to have a clearer understanding of its rationale. Also, the number of individuals providing alert and intervention processes have to expanded so that all the students get adequate and timely support. Most importantly, robust program evaluation mechanisms are needed so that evidence of program success is communicated to all stakeholders for them to appreciate the program benefits.

\section{References}

Bergman, M. (2008). Advances in Mixed Methods Research: Theories and Application. London : SAGE.

Council on Higher Education (CHE). (2012). Access and throughput in South African Higher Education. Three case studies Council on Higher Education. South Africa, Department of Higher Education and Training. Pretoria: Council on Higher Education .

Creswell, J. (2009). Research Design: Qualitative, Quantitative and Mixed Methods Approches (3 erd.). Thousand Oak: SAGE.

Cuseo, J. (2006). Red flags behavioural indicators of potential student attrition. Message to fye-list serve. In Lynch-Holmes, K.,Troy, A. B., \& Ramos I. (2012).White paper on Early Alert and Retention top practices for student retention . Connect Edu. Department of Higher Education (1997). Higher Education Act 101:The Programme for Transformation. Pretoria.

Plessis, S. (2005, September 26-27). Cracking the tracking code:Creating a Tracking system that supports teaching and learning. Cape Town, Western Cape, South Africa: Tracking and Monitoring Workshop organised by the Council on higher Education.

Ewell, P. (1995). Student tracking: New techniques, new demands. San Francisco: Jossey Bass.

Johnson, B. \& Christensen,L. (2012). Educational Research: Quantitiative, Qualitative and Mixed Approaches. (4th Edition ed.). Far Est Square: SAGE Publications.

Kuh, G. (2007c, June 12). How to help students succeed. Chronicle of Higher education, pp. B12-13.

Leedy, P. D. and Ormrod, J. E. (2010). Practical Research: Planning and Design (9th Edition ed.). Pearson.

Lemmens, J. (2010). Students readiness for university education. University of Pretoria. Pretoria: Unpublished doctoral thesis.

Letseka, M.,Breier,M. (2007). Student dropout in higher education. The impact of higher education drop out on poverty. Ch 6. 83-101. In Letseka and Breir (Ed).Human Sciences Research Council

Letseka, M., \& Maile,S. (2008). High university dropout rates: a threat to South Africa's future. Pretoria: Human Sciences Rearsearch Council.

Krause, L. (2005). Serious thoughts about dropping out in first year. Studies in Learning , Evaluation and Innovation , 2 (3), 55-68. 
Madiny, D. (2005). Student tracking and monitoring systems. Present work on monitoring student success in South Africa and Australian higher education. University of Western Cape. Council on Higher Education

Makura, A., Skead, M. and Nhundu, K (2011). Academic development practices at Fort Hare University. An epitome of University Success. Research in Higher Education, 12, 13-22

Maree, K. (2007). First steps in research. Pretoria. Van Schaik Publishers.

Sarantakos, S. ( 2005). Social research (3rd Ed.). London: Macmillan.

Scott, I., Yield, N., Hendry, J. (2007). A Case for Improving Teaching and Learning in South African Higher Education. Centre for Higher Education Development. Pretoria: Council on Higher Education .

Siedman, A. (2005). College Student Retention: Formula for Success. Westport CT: Praeger.

Seale, C. (2012). Researching Society and Culture. (3rd ed). Silverman, D. (2011). Qualitative Research: Issue of Theory Methods and Practice (3rd ed.). London: SAGE.

Tashakkori, A., \& Teddlie, S. (2009). A handbook of mixed methods in socials and behavioural sciences. Thousand Oaks: SAGE. Tampke, D. (2012). Developing, implementing and assessing an ealry aelrt system. Journal of College student retention , 523-532.

Tinto, V. (2005). Reflections on retention and persistence: Institutional actions on behalf of student persistence. Studies in Learning , Evaluation, Innovation and Development, 2 (3), 9-97 